\title{
Diarylquinoline compounds induce autophagy-associated cell death by inhibiting the Akt pathway and increasing reactive oxygen species in human nasopharyngeal carcinoma cells
}

\author{
YUCHEN CAI ${ }^{1,2^{*}}$, ZHIHUI WANG ${ }^{3 *}$, TIEMIN SUN $^{4}$, YANXIA SHI $^{1,5}$, \\ YUELI SUN ${ }^{1,2}$, PEIYU HUANG ${ }^{1,5}, \mathrm{SU}_{\text {LI }}^{1,5}$ and WENQI JIANG ${ }^{1,5}$ \\ ${ }^{1}$ State Key Laboratory of Oncology in South China; ${ }^{2}$ Research Department, Sun Yat-sen University Cancer Center, \\ Guangzhou, Guangdong; ${ }^{3}$ Department of Medical Oncology, The Fifth Affiliated Hospital, \\ Sun Yat-sen University, Zhuhai, Guangdong; ${ }^{4}$ Shenyang Pharmaceutical University, Shenyang, Liaoning; \\ ${ }^{5}$ Department of Medical Oncology, Sun Yat-sen University Cancer Center, Guangzhou, Guangdong, P.R. China
}

Received September 16, 2012; Accepted October 25, 2012

DOI: $10.3892 /$ or.2012.2207

\begin{abstract}
Diarylquinoline compounds are newly synthesized derivatives of the new anti-tuberculosis drug, TMC207. In this study, nine diarylquinoline compounds were screened for cytotoxic activity against human tumor cells, and their mechanisms of action were investigated. Among the nine compounds, STM-57 [N-((6-bromo-2-methoxyquinolin-3-yl) (phenyl)methl)- $N$-(3,4-dichlorophenyl)-3-(4 -methylpiperazin1-yl)propanamide] showed potent cytotoxic activity. STM-57 induced caspase-independent cell death in the human nasopharyngeal carcinoma cell line, CNE-2. Further investigation showed that STM-57 induced autophagy, as determined with the increased expression of green fluorescent protein-light chain 3 (GFP-LC3) and increased LC3-II levels. STM-57 inhibited the phosphorylation of Akt and the mammalian target of rapamycin (mTOR) in CNE-2 cells. The intracellular calcium concentration and reactive oxygen species levels were increased in CNE-2 cells following treatment with STM-57, whereas the mitochondrial transmembrane potential $(\Delta \Psi \mathrm{m})$ and ATP concentrations were decreased.
\end{abstract}

\section{Introduction}

As a response to nutrient restriction, autophagy is an intracellular pathway in which cytosolic elements and even organelles are enclosed in double-membrane vesicles known

Correspondence to: Professor Wenqi Jiang or Dr Su Li Department of Medical Oncology, Sun Yat-sen University Cancer Center, 651 Dongfeng East Road, Guangzhou, Guangdong 510060, P.R. China E-mail: jiangwenqi2009@126.com

E-mail: lisu@sysucc.org.cn

*Contributed equally

Key words: diarylquinoline compounds, anticancer, caspaseindependent cell death, autophagy as autophagosomes (1-4). The physiological role of autophagy is to degrade long-lived proteins and damaged organelles to ensure the survival of cells during starvation (5). However, autophagy also plays pathophysiological roles. In cancer, it acts as a protector against certain cancer treatments and, most importantly, prevents cell death in a hostile microenvironment. Previous studies have indicated that autophagy plays a key role in tumor cell resistance to chemotherapy, and that the inhibition of autophagy can enhance the cytotoxicity of certain chemotherapeutic agents $(6,7)$. By contrast, other cancer cells undergo autophagic cell death following various anticancer therapies (8). As an alternative cell death pathway, called programmed cell death type II or autophagic cell death has morphological and biochemical features distinguishing it from apoptosis and necrosis.

Autophagy is regulated by the autophagy-related (Atg) genes that control the formation of autophagosomes (9). Beclin 1, the mammalian ortholog of yeast Atg6/Vps30, was originally discovered in a yeast two-hybrid screen as a Bcl-2interacting protein, and it was the first human protein shown to be indispensable for autophagy (10). Beclin 1 is a component of a complex consisting of the class III phosphatidylinositol 3-kinase (PI3K) that stimulates autophagy. The interaction between Beclin 1 and its binding partners regulates the initial steps of autophagy. Beclin 1 also possesses the so-called $\mathrm{BH} 3$ domain (amino acids 114-123) that mediates its interaction with Bcl-2 and other close Bcl-2 homologs, such as Bcl-xL and Mcl-1 $(11,12)$. The induction of Beclin 1 expression can be observed during autophagy in various cell types (13).

A number of signaling pathways are involved in the regulation of autophagy. The serine/threonine kinase mammalian target of rapamycin complex 1 (mTORC1) is a major negative regulator of autophagy $(14,15)$. The key upstream regulators of mTORC1 include the class I PI3K-Akt pathway and the AMP-activated protein kinase (AMPK) pathway. The Akt kinase phosphorylates the mTORC1 repressor, tuberous sclerosis complex 2 (TSC2), thus leading to the activation of mTORC1 and the subsequent inhibition of the expression and function of Atg proteins (16). The class I PI3K/Akt signaling 
molecules link receptor tyrosine kinases to mTORC1 activation and thereby repress autophagy in response to a sufficient amount of growth factors (17). In addition to Akt, one of the main mTORC1 regulators is AMPK, which maintains energy homeostasis by inducing autophagy and blocking protein synthesis and cell proliferation, mainly through the phosphorylation of its downstream target, raptor, and the consequent inhibition of mTORC1 in response to starvation and calcium signals (18).

Reactive oxygen species (ROS) consist of a group of highly reactive molecular forms of oxygen containing unpaired electrons that are continuously produced as a byproduct of the mitochondrial respiratory chain in normal cells $(19,20)$. Due to their high reactivity, certain long half-life ROS can oxidize cell constituents and damage cell structures and functions. ROS damage has been shown to cause various types of cell death, including apoptosis and autophagy $(21,22)$. Compared with normal cells, tumor cells have long-term high levels of ROS; therefore, the redox system of tumor cells is more vulnerable to drugs that can increase ROS levels compared to normal cells $(23,24)$.

Quinoline compounds are widely used as 'parental' compounds to synthesize molecules with medical benefits, particularly those with anti-malarial and anti-microbial activities. Certain quinoline-based compounds have shown effective anticancer activity. Diarylquinoline compounds have recently been shown to exert anti-proliferative effects on cancer cell lines (25-27). In our study, nine diarylquinoline compounds were newly synthesized based on the parental structure of a new anti-tuberculosis drug, TMC207. These compounds were then screened for their cytotoxic activity against human tumor cells, and their mechanisms of action were investigated.

\section{Materials and methods}

Compounds and reagents. All nine of the new compounds were synthesized by Shenyang Pharmaceutical University. The chemical structures of these compounds are presented in Fig. 1 and include the following: STM-57, $N$-((6-bromo-2-methoxyquinolin-3-yl)(phenyl)methl)- $N$-(3,4-dichlorophenyl)-3-(4methylpiperazin- 1-yl)propanamide; STM-35, $N$-((6-bromo2-methoxyquinolin-3-yl)(phenyl)methyl)-3-(1H-imidazol1-yl)- $N$-phenylpropanamide; STM-39, $N$-((6-bromo-2methoxyquinolin-3-yl)(phenyl)methyl)-3-morpholino- $N$ phenylpropanamide; STM-91, $N$-((6-bromo-2-methoxyquinolin3 -yl)(phenyl)methyl)-3-morpholino- $N$-(p-tolyl) propanamide; STM-143, 2-(benzyl (methyl) amino)- $N$-((6-bromo-2- hydroxyquinolin-3-yl)(phenyl)methyl)- $N$-phenylacetamide; STM-73, $N$-((6-bromo-2-methoxyquinolin-3-yl)(phenyl)methyl)- $N(4-$ methoxyphenyl)-2-morpholinoacetamide; STM-99, $N$-((6bromo-2-methoxyquinolin-3-yl)(phenyl) methyl)-4-chloro- $N$ (2-(dimethylamino)ethyl)benzamide; STM-157, $N$-((6-bromo2-hydroxyquinolin-3-yl)(phenyl)methyl)-3-(dimethylamino)- $N$ (p-tolyl) propanamide; and STM-120, $(R)-(S)$-2-benzamido-3phenylpropyl-2-(2-hydroxybenzamido)-3-phenylpropanoate. All the compounds were initially dissolved in $100 \%$ dimethyl sulfoxide (DMSO). 3-(4,5-dimethylthiazol-2-yl)-2,5-diphenyl tetrazolium bromide (MTT) was purchased from Sigma Co. (Sigma-Aldrich). RPMI-1640, DMEM and McCoy's 5A were purchased from Invitrogen.
Cell lines and culture. The human nasopharyngeal carcinoma cell lines, CNE-1 and CNE-2, the human lung adenocarcinoma cell line, A549, the human acute promyelocytic leukemia cell line, HL-60, and the human Burkitt's lymphoma cell line, Raji, were cultured in RPMI with $10 \%$ fetal bovine serum (FBS). The human breast carcinoma cell lines, MDA-MB-231 and MCF-7, and its related MDR cell line, MCF-7/ADM, were maintained in DMEM with $10 \%$ FBS. The human colon cancer cell line, HT-29, was cultured in McCoy's 5A medium with $10 \%$ FBS. The cells were incubated at $37^{\circ} \mathrm{C}$ in a humidified incubator in $5 \% \mathrm{CO}_{2}$.

Cell growth inhibition test. The cells were plated in a 96-well plate and cultured in medium with various concentrations of the test compounds added after $24 \mathrm{~h}$. After an incubation of $68 \mathrm{~h}, 20 \mu \mathrm{l}$ of MTT were added to each well (100 $\mu \mathrm{g} / \mathrm{well})$ and incubated for an additional $4 \mathrm{~h}$, and the liquid in the wells was then evaporated. The insoluble formazan produced was dissolved with $200 \mu 1 \mathrm{DMSO}$, and the optical density was measured with an ELISA reader (Thermo Labsystems, Espoo, Finland) at wavelengths of 570 and $630 \mathrm{~nm}$. The experiments were performed in triplicate. From these results, the percentage of live cells in each well was estimated and plotted against the drug concentrations as dose-response curves, from which the $\mathrm{IC}_{50}$ value was derived.

Cell cycle detection. The cells were collected, resuspended in $1 \mathrm{ml}$ pre-cooled $70 \%$ ethanol, and fixed overnight at $4^{\circ} \mathrm{C}$. After the ethanol was removed, $0.5 \mathrm{ml}$ staining solution [50 $\mathrm{mg} / \mathrm{ml}$ propidium iodide (PI), $100 \mathrm{mg} / \mathrm{ml} \mathrm{RNaseA}$, and $0.2 \%$ Triton X-100] was added, and the cells were incubated at $37^{\circ} \mathrm{C}$ for $30 \mathrm{~min}$ in the dark. The cell cycle distribution was immediately analyzed with flow cytometry (Beckman Coulter, Fullerton, CA) at a wavelength of $488 \mathrm{~nm}$.

Annexin V-FITC/PI staining assay. Cells exposed to different treatments were collected, resuspended in $100 \mu \mathrm{l}$ PBS, adjusted to approximately $1 \times 10^{6}$ cells $/ \mathrm{ml}$, and transferred to a microfuge tube $(0.5 \mathrm{ml})$. After the addition of $10 \mu \mathrm{l}$ binding reagent and $1.25 \mu \mathrm{l}$ Annexin V-FITC, the cells were incubated at room temperature for $15 \mathrm{~min}$ in the dark. The cells were then centrifuged, and the medium was removed. The cells were resuspended in $0.5 \mathrm{ml}$ cold binding buffer (10 mM HEPES, $150 \mathrm{mM} \mathrm{NaCl}$, $2.5 \mathrm{mM} \mathrm{CaCl}_{2}, 1 \mathrm{mM} \mathrm{MgCl}_{2}$ and 20\% BSA, pH 7.4), and $10 \mu \mathrm{l}$ (PI, $30 \mathrm{mg} / \mathrm{ml}$ ) was added. The samples were placed on ice in the dark. Apoptosis was immediately analyzed with flow cytometry (Beckman Coulter) at a wavelength of $488 \mathrm{~nm}$.

Confocal microscopy and indirect immunofluorescence. CNE-2 cells were grown on glass coverslips and transfected with an expression vector containing the LC3 gene fused to green fluorescent protein (GFP-LC3). At $24 \mathrm{~h}$ after transfection, the cells were treated with STM-57 and analyzed after an additional $12 \mathrm{~h}$. The cells were fixed with $4 \%$ paraformaldehyde in PBS for $30 \mathrm{~min}$ at room temperature, and the slides were mounted in anti-fade solution and stored at $4^{\circ} \mathrm{C}$. The coverslips were viewed with a laser-scanning confocal microscope (Olympus, FV1000).

Electron microscopy. The cells were fixed by immersion in a mixture of $2.5 \%$ glutaraldehyde, $2.5 \%$ paraformaldehyde 


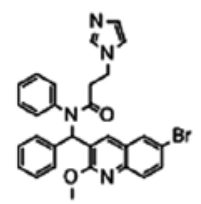

N-((6-bromo-2-methoxyquinolin-3-yl) (phenyl)methyl)-3-(1H-imidazol-1-yl) - $\mathrm{N}$-phenylpropanamide

STM-35

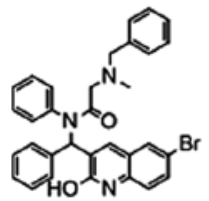

2-(benzyl(methyl)amino) -N-((6-bromo-2-hydroxyquinolin-3-yl) (phenyl)methyl)- $\mathrm{N}$-phenylacetamide

STM-143

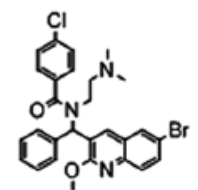

$N$-((6-bromo-2-methoxyquinolin-3-yl) (phenyl)methyl)-4-chloro- $\mathrm{N}$ (2-(dimethylamino)ethyl)benzamide

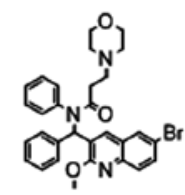

N-((6-bromo-2-methoxyquinolin-3-yl) (phenyl)methyl)-3-morpholino - $\mathrm{N}$-phenylpropanamide

STM-39

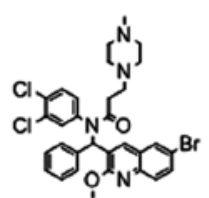

$\mathrm{N}$-((6-bromo-2-methoxyquinolin-3-yl) (phenyl)methyl)- $\mathrm{N}$-(3,4-dichlorophenyl) -3-(4-methylpiperazin-1-yl)propanamide

STM-57

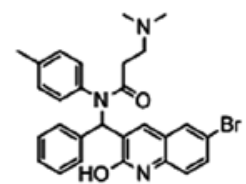

N-((6-bromo-2-hydroxyquinolin-3-yl) (phenyl)methyl)-3-(dimethylamino)

- $\mathrm{N}$-(p-tolyl)propanamide

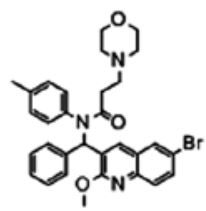

N-((6-bromo-2-methoxyquinolin-3-yl)
(phenyl)methyl)-3-morpholino $-N$-(p-tolyl)propanamide

STM-91

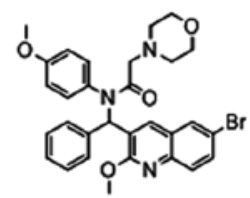

$\mathrm{N}$-((6-bromo-2-methoxyquinolin-3-yl) (phenyl)methyl)- $N$-(4-methoxyphenyl)

-2-morpholinoacetamide

STM-73

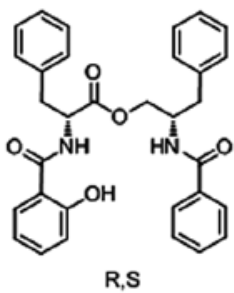

$(R)$-(S)-2-benzamido-3-phenylpropyl 2-(2-hydroxybenzamido)-3-phenylpropanoate

STM-120

STM-99

STM-157

Figure 1. Molecular structures of the nine newly synthesized diarylquinoline compounds.

and $0.05 \%$ picric acid in $0.067 \mathrm{M}$ cacodylate buffer ( $\mathrm{pH} 7.4)$. Post-fixation was performed in $1 \%$ osmium tetroxide followed by an overnight immersion in $0.3 \%$ uranyl acetate dissolved in $50 \mathrm{mM}$ maleate buffer ( $\mathrm{pH}$ 5.0). Standard procedures for dehydration and embedding in Epon were used. Thin sections were further stained with lead citrate and examined with an electron microscope (Philip, CN10).

Western blot analysis. Lysates were prepared from $4 \times 10^{5}$ cells by dissolving cell pellets in $100 \mu 1$ of lysis buffer [ $20 \mathrm{mM}$ $\mathrm{Na}_{2} \mathrm{PO}_{4}$ (pH 7.4), $150 \mathrm{mM} \mathrm{NaCl}, 1 \%$ Triton X-100, $1 \%$ aprotinin, $1 \mathrm{mM}$ phenymethysulfonyl fluoride, $10 \mathrm{mg} / \mathrm{ml}$ leupeptin, $100 \mathrm{mM} \mathrm{NaF}$ and $\left.2 \mathrm{mM} \mathrm{Na}_{3} \mathrm{VO}_{4}\right]$. The lysates were centrifuged at $14,000 \mathrm{x} \mathrm{g}$ for $20 \mathrm{~min}$, and the supernatant was collected. The protein content was determined using the Bio-Rad protein assay. SDS-PAGE sample buffer [10 mM Tris-HCl, $\mathrm{pH} 6.8$, $2 \%$ SDS, $10 \%$ glycerol and $0.2 \mathrm{M}$ dithiothreitol (DTT)] was added to the lysates. A total of $50 \mu \mathrm{g}$ of protein was loaded in each well of a 5-12\% SDS-PAGE gel. The resolved proteins were electrophoretically transferred onto PVDF membranes (Roche, Mannheim, Germany) and blocked with TBS with 5\% non-fat milk overnight at $4^{\circ} \mathrm{C}$. The membranes were then incubated with the primary antibody. After washing, the membranes were incubated with the secondary anti-mouse/anti-rabbit antibody (1:1,000, HRP-labeled; Dako) at room temperature for $1 \mathrm{~h}$. After washing, the bound antibody complex was detected using LumiGLO reagent [Cell Signaling Technology, Inc. (CST) \# 7003] and XAR film (Kodak, XBT-1), as described by the manufacturers. The following primary antibodies were used: caspase 3 (CST \#9662), poly(ADP-ribose) polymerase (PARP) (sc-7150), glyceraldehyde 3-phosphate dehydrogenase (sc-47724; both from Santa Cruz Biotechnology, Inc.), LC3 (NB100-2220; Novus Biologicals), Beclin 1 (CST \#3738), Bcl-2 (CST \#2870), Bcl-xL (CST \#2762), phospho-Akt (ser473; CST \#4058), Akt1 (CST \#2967), phospho-mTOR (ser2448; CST \#2971) and mTOR (CST \#4517) antibodies.

Measurement of mitochondrial membrane potential ( $\Delta \Psi \mathrm{m})$. $\Delta \Psi \mathrm{m}$ was determined by the retention of the dye $\mathrm{DiOC}_{6}(3)$. Cells were harvested and washed twice with PBS. After incubation with $50 \mathrm{nM} \mathrm{DiOC}_{6}(3)$ at $37^{\circ} \mathrm{C}$ for $30 \mathrm{~min}$, the cells were washed again and analyzed by flow cytometry.

Analysis of intracellular $\mathrm{Ca}^{2+}$ concentration. The changes of intracellular $\mathrm{Ca}^{2+}$ concentration were determined by the fluorescent dye, Fluo-3/AM. Cells were washed twice with PBS and incubated with $5 \mu \mathrm{M}$ Fluo- $3 / \mathrm{AM}$ at $37^{\circ} \mathrm{C}$ for $30 \mathrm{~min}$. Subsequently, the cells were washed and analyzed by flow cytometry.

Measurement of intracellular ROS. Intracellular ROS production was measured by using the fluorescent dye, dichlor- 
A

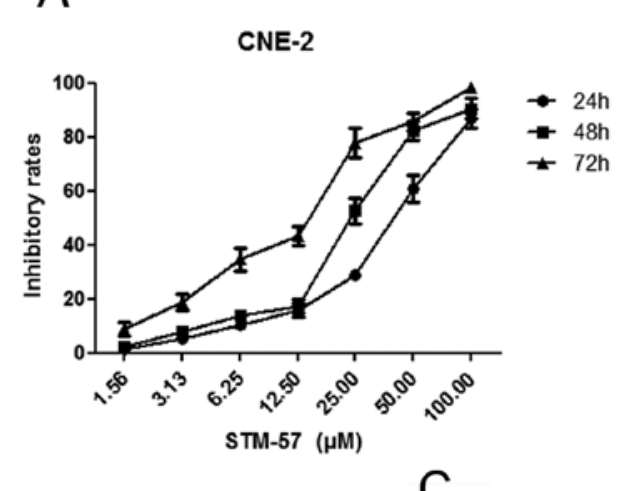

B

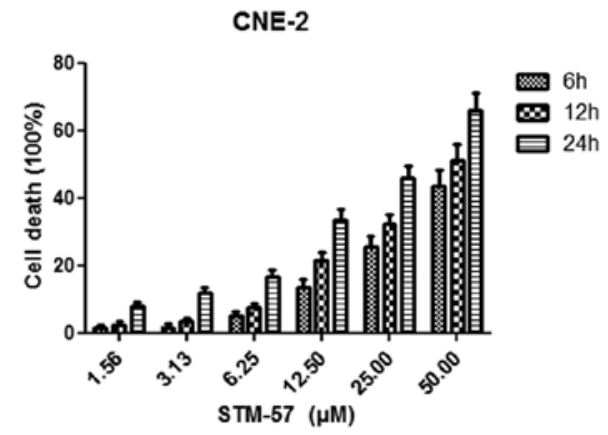

CNE-2

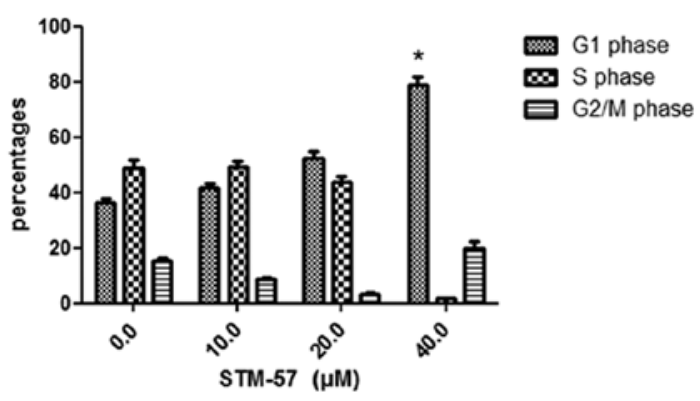

Figure 2. Growth inhibition of CNE-2 cells by STM-57. (A) CNE-2 cells were plated at 8,000 cells/well in a 96-well plate. STM-57 was then added to the wells The cells were cultured for $72 \mathrm{~h}$, and an MTT assay was performed. (B) The cell death rates in CNE- 2 cells after 6, 12 or $24 \mathrm{~h}$ treatment with STM-57 detected with the trypan blue assay. (C) CNE-2 cells were treated with the indicated concentrations of STM-57 for $12 \mathrm{~h}$, and the DNA content was analyzed by flow cytometry. The results are representative of three experiments (" $\mathrm{P}<0.05$ compared with the control group).

fluorescein-diacetate (DCFH-DA), which can be converted to DCFH by esterases when the cells take it up. DCFH reacts with ROS to form a new highly fluorescent compound, dichlorofluorescein, which can be analyzed by flow cytometry. The treated cells were incubated with DCFH-DA $(10 \mu \mathrm{M})$ at $37^{\circ} \mathrm{C}$ for $1 \mathrm{~h}$, and then measured by flow cytometry.

Statistic analysis. All the data were obtained from at least three independent experiments. The comparisons of the various treatment protocols were performed with a one-way analysis of variance (ANOVA) using SPSS software to obtain the P-value for comparisons between treatments. $\mathrm{P}<0.05$ was considered the minimal level of significance.

\section{Results}

Antitumor activity screening of diarylquinoline compounds. The nine diarylquinoline compounds (Fig. 1) demonstrated anti-proliferative activity in human nasopharyngeal carcinoma, lung adenocarcinoma, breast cancer, colon cancer, leukemia and lymphoma cell lines. As shown in Table I, the $\mathrm{IC}_{50}$ values ranged from $9.9 \pm 0.9$ to $123.3 \pm 20.4 \mu \mathrm{M}$. Among these compounds, STM-57, STM-35, STM-91, STM-99 and STM-157 showed the most potent anti-proliferative activity in the cancer cell lines.

STM-57-induced caspase-independent cell death in CNE-2 cells. STM-57 resulted in the inhibition of cell growth in a concentration- and time-dependent manner in CNE-2 cells, and the $\mathrm{IC}_{50}$ value was $10.2 \pm 4.8 \mu \mathrm{M}$ (Fig. $2 \mathrm{~A}$ and $\mathrm{B}$ ). The inhibition of cell growth may be the result of the induction of apoptosis, autophagy and/or cell cycle arrest.

CNE-2 cells were treated with 10, 20 and $40 \mu \mathrm{M}$ STM-57 for $12 \mathrm{~h}$, and the cell cycle distribution was analyzed by flow cytometry. STM-57 $(40 \mu \mathrm{M})$ significantly induced G1-phase arrest by $78.8 \pm 3.1 \%$ compared with $36.2 \pm 1.8 \%$ in the control group (Fig. 2C).

To further confirm that STM-57 mainly induced nonapoptotic cell death, CNE-2 cells treated with 20 and $40 \mu \mathrm{M}$ STM-57 for $24 \mathrm{~h}$ were analyzed using the Annexin V-FITC/PI staining assay. As shown in Fig. 3A, the highest apoptotic rates were $0.3 \%$ in the CNE- 2 cells following treatment. The DNA ladder was not detected after STM-57 treatment (data not shown). These results strongly suggest that STM-57 induces non-apoptotic cell death in CNE-2 cells.

To determine whether the cell death was caspase-dependent, we first detected the cleavage of caspase 3 . As a positive control, cisplatin (DDP) induced the cleavage of caspase 3 and PARP in the CNE- 2 cells. Pro-caspase 3 was cleaved to yield a $17 \mathrm{kDa}$ fragment and PARP was cleaved to an $89 \mathrm{kDa}$ fragment following DDP treatment (Fig. 3B). However, the cleavage of caspase 3 was not observed following treatment with STM-57. The cleavage of PARP was also undetectable (Fig. 3C). This result further confirmed the results that STM-57 induced caspase 3-independent cell death.

\section{STM-57 induces cell autophagy-associated cell death in CNE-2 cells}

STM-57 induces the formation of autophagosomes. To observe autophagy, CNE-2 cells were stained with monodan- 
Table I. Anti-proliferative activity of the nine newly synthesized diarylquinoline compounds in human cancer cell lines.

\begin{tabular}{lrrrrrrrrr}
\hline & \multicolumn{7}{c}{ Cell line } \\
\cline { 2 - 9 } Compound & CNE-1 & CNE-2 & A549 & MCF-7 & MCF-7/ADM & MDA-MB-231 & HT-29 & HL-60 & Raji \\
\hline STM-57 & $10.8 \pm 2.2$ & $10.2 \pm 4.8$ & $12.3 \pm 2.1$ & $10.8 \pm 2.9$ & $11.9 \pm 2.5$ & $20.1 \pm 1.1$ & $29.2 \pm 13.0$ & $12.4 \pm 2.6$ & $13.5 \pm 2.2$ \\
STM-35 & $10.8 \pm 2.7$ & $21.5 \pm 2.4$ & $15.6 \pm 2.7$ & $12.8 \pm 2.2$ & $17.7 \pm 2.5$ & - & - & $21.1 \pm 2.1$ & $22.3 \pm 2.0$ \\
STM-39 & $23.6 \pm 2.6$ & $46.1 \pm 2.9$ & $46.7 \pm 3.2$ & $47.0 \pm 4.2$ & $45.7 \pm 4.2$ & - & - & $45.4 \pm 3.5$ & $45.5 \pm 2.2$ \\
STM-73 & $55.8 \pm 3.2$ & $52.6 \pm 5.2$ & $67.9 \pm 4.4$ & $64.5 \pm 5.1$ & $122.9 \pm 11.2$ & - & - & $55.3 \pm 2.2$ & $57.3 \pm 3.5$ \\
STM-91 & $19.7 \pm 2.5$ & $23.5 \pm 4.2$ & $20.4 \pm 4.8$ & $10.8 \pm 2.2$ & $17.3 \pm 5.3$ & $10.7 \pm 1.0$ & $32.4 \pm 5.5$ & $24.6 \pm 3.4$ & $27.5 \pm 4.8$ \\
STM-99 & $30.9 \pm 2.4$ & $26.4 \pm 4.7$ & $21.4 \pm 2.4$ & $19.1 \pm 4.4$ & $14.4 \pm 4.6$ & $18.5 \pm 1.1$ & $21.0 \pm 2.8$ & $21.2 \pm 4.4$ & $21.1 \pm 2.2$ \\
STM-120 & $32.4 \pm 3.1$ & $36.2 \pm 3.9$ & $101.8 \pm 5.4$ & $30.5 \pm 6.4$ & $123.3 \pm 20.4$ & - & - & $53.2 \pm 2.4$ & $53.4 \pm 4.3$ \\
STM-143 & $41.3 \pm 3.4$ & $83.2 \pm 4.5$ & $91.9 \pm 3.7$ & $45.6 \pm 2.4$ & $44.8 \pm 4.9$ & - & - & $46.8 \pm 4.6$ & $47.7 \pm 3.6$ \\
STM-157 & $35.2 \pm 4.6$ & $26.5 \pm 3.6$ & $36.9 \pm 5.6$ & $11.8 \pm 0.3$ & $34.9 \pm 4.0$ & $9.9 \pm 0.9$ & $10.0 \pm 2.1$ & $34.3 \pm 4.1$ & $32.2 \pm 2.6$ \\
\hline
\end{tabular}

Data are the $\mathrm{IC}_{50}$ values (means $\pm \mathrm{SD}$ ), $\mu \mathrm{M}$ of the compounds listed. -, not determined.

A
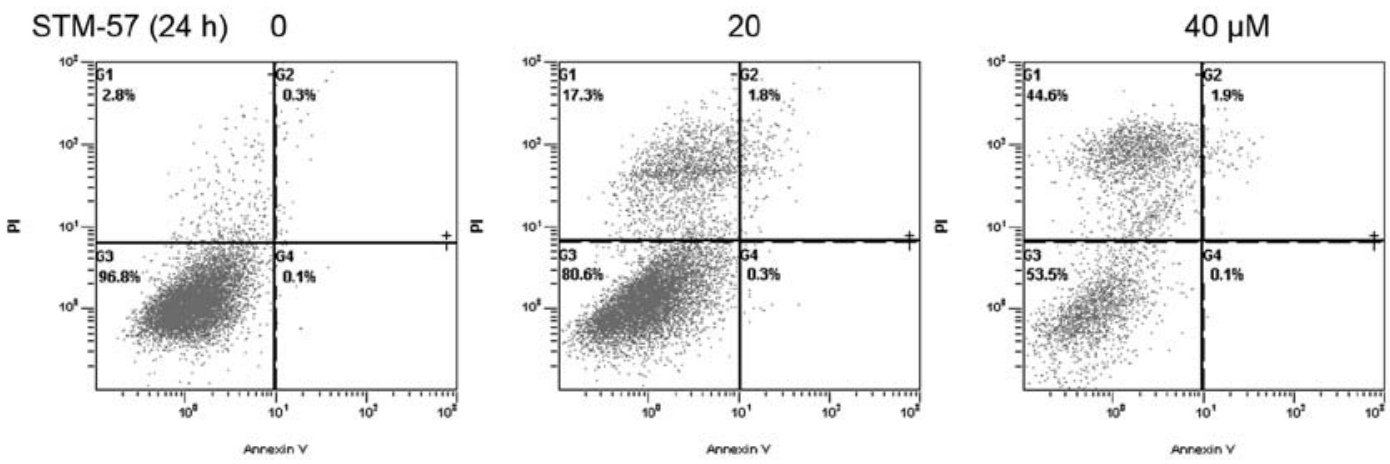

B

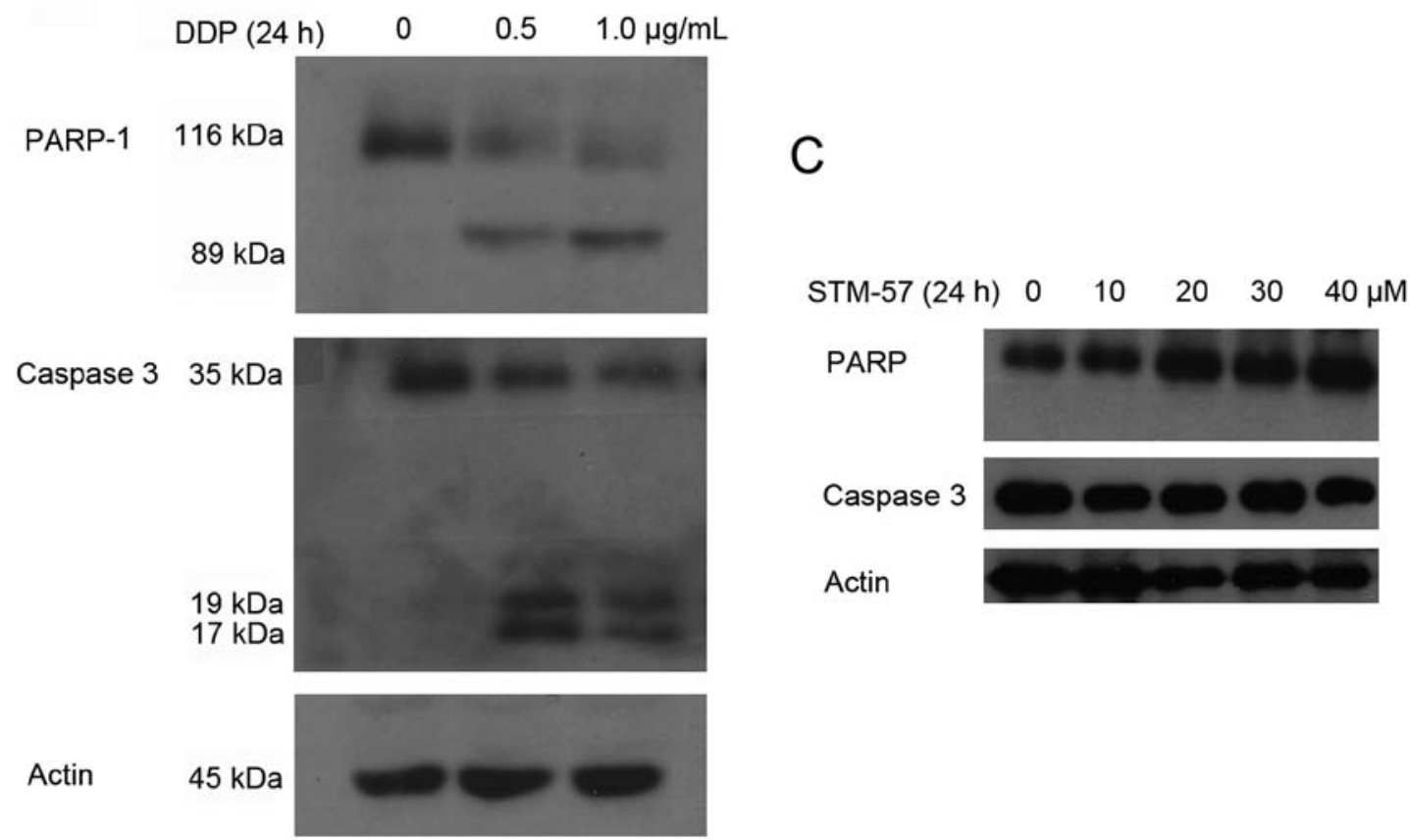

Figure 3. STM-57 induces caspase-independent cell death in CNE-2 cells. (A) CNE-2 cells were treated with 0,20 and $40 \mu$ M STM-57 for 24 h. Following treatment, the cells were collected, stained with Annexin V and PI and analyzed by flow cytometry. (B) CNE-2 cell lysates were prepared after treatment with $0,0.5$ or $1.0 \mu \mathrm{g} / \mathrm{ml}$ DDP for $24 \mathrm{~h}$. (C) CNE-2 cell lysates were prepared after treatment with $0,10,20,30$ or $40 \mu \mathrm{M} \mathrm{STM}-57$ for $24 \mathrm{~h}$. A western blot analysis was conducted with caspase-3 and PARP antibodies. 
A

DAPI

GFP-LC3
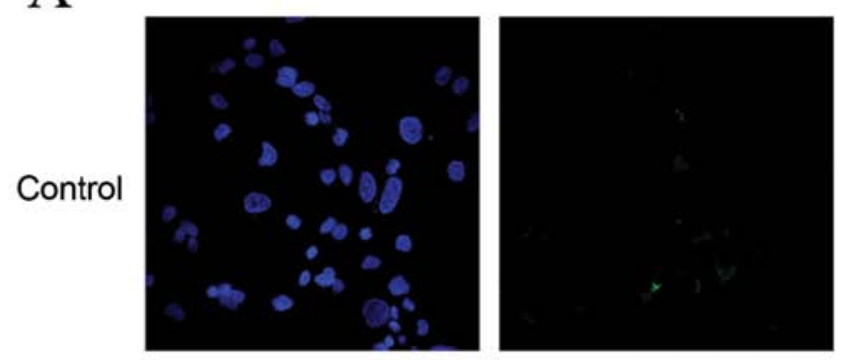

Merge
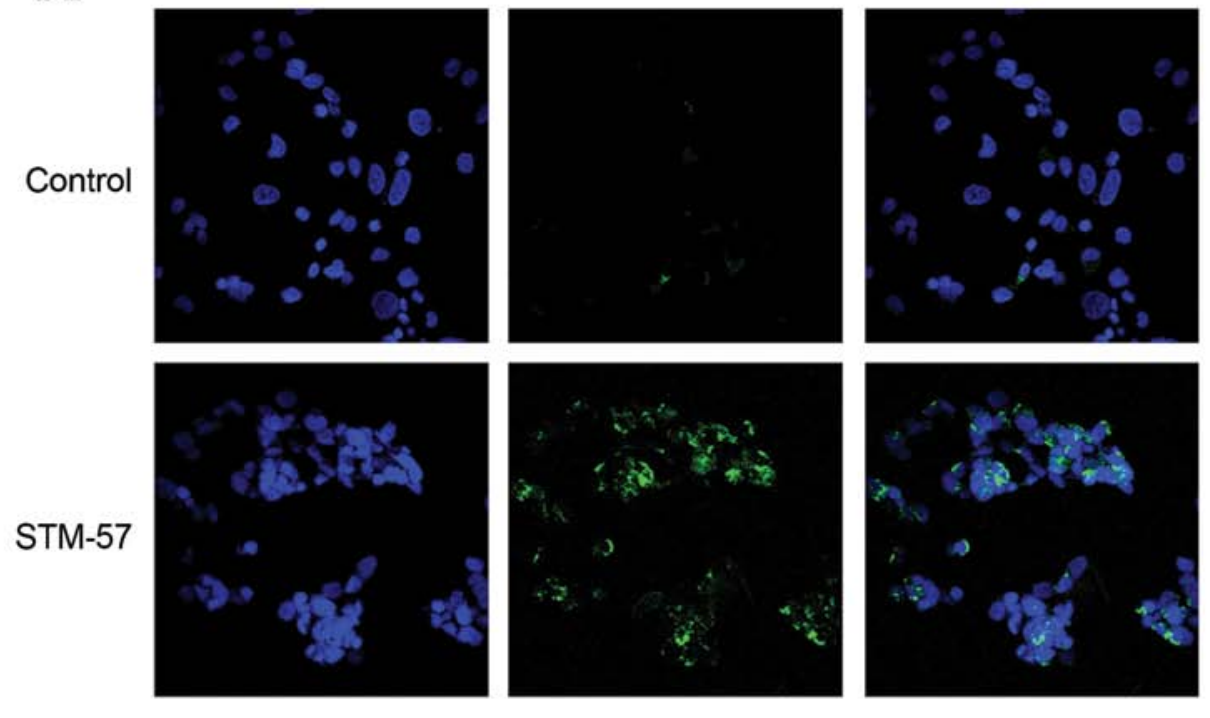

B

C

CNE-2
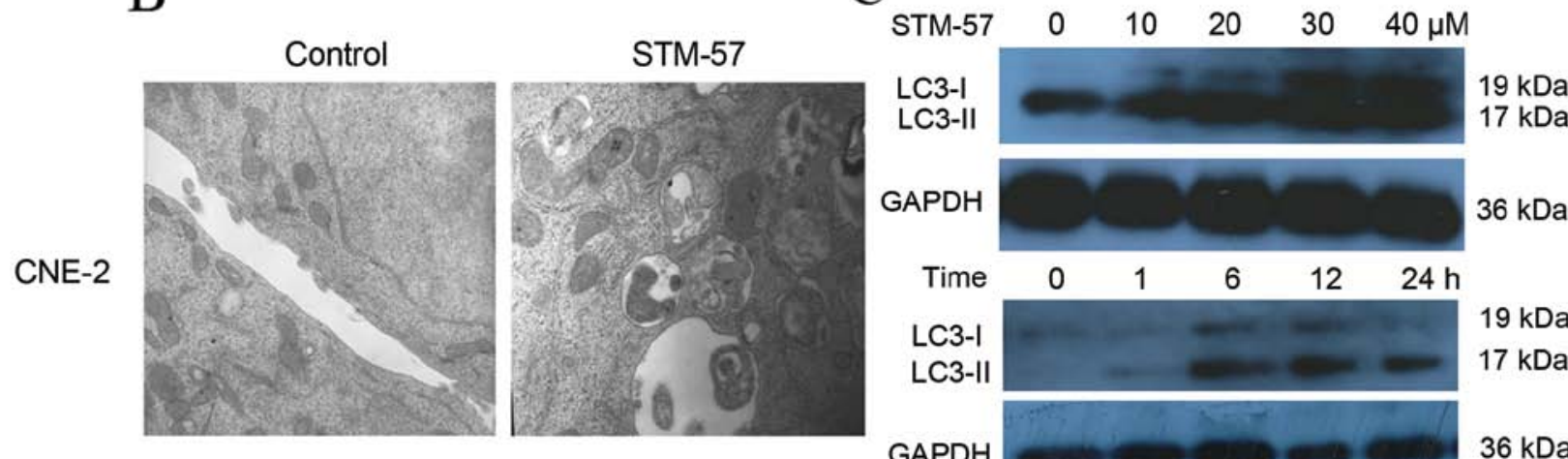

GAPDH

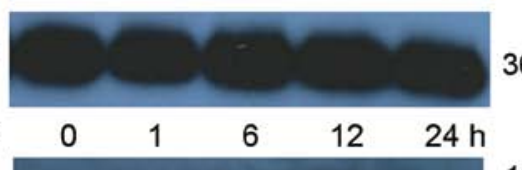

$36 \mathrm{kDa}$

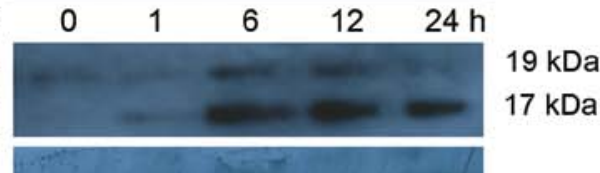

$36 \mathrm{kDa}$

Figure 4. STM-57 induces autophagy in CNE-2 cells. (A) CNE-2 cells were transfected with a construct expressing LC3 fused to green fluorescent protein (GFP-LC3) for $24 \mathrm{~h}$. The cells were then treated with or without $20 \mu \mathrm{M} \mathrm{STM}-57$ for $24 \mathrm{~h}$ and visualized under a confocal microscope. (B) An electron micrograph showing autophagic vacuoles of CNE-2 cells following treatment with $20 \mu \mathrm{M} \mathrm{STM-57}$ for $24 \mathrm{~h}$. (C) STM-57 dose- and time-dependently induced the formation of LC3-II, a marker of autophagy. CNE- 2 cells were treated with $0,10,20,30$ or $40 \mu \mathrm{M}$ STM-57 for $24 \mathrm{~h}$ or $20 \mu \mathrm{M}$ STM-57 for the indicated times. The lysates were analyzed with immunoblotting with the LC3 antibody.

sylcadaverine (MDC) (data not shown) or transfected with GFP-LC3. Following treatment with STM-57, a significant accumulation of GFP-LC3 was observed, indicating the association of GFP-LC3 with autophagosomal membranes following the induction of autophagy (Fig. 4A). The ultrastructural analysis of the STM-57-treated CNE-2 cells using electron microscopy showed large, ragged cytomembranes and swollen mitochondria in the autophagic vacuoles in contrast to the control cells, in which no such vacuoles were detected (Fig. 4B). These results suggest that STM-57 induces the formation of autophagosomes.

STM-57 induces LC3-II expression in CNE-2 cells. The membrane-associated light chain 3 protein (LC3, Atg8) is a key marker of autophagy. After the induction of autophagy, LC3-I is converted to LC3-II, which is most likely conjugated to phosphatidylethanolamine (PE) and tightly bound to the autophagosomal membranes, forming ring-shaped structures in the cytoplasm. The amount of PE-conjugated LC3 (LC3-II) correlates well with the number of autophagosomes. After
STM-57 treatment for the indicated times, LC3 was detected with immunoblot analysis. The results indicated that the expression of LC3-II was gradually upregulated (Fig. 4C). These data confirmed the results of GFP-LC3 transfection and indicated that STM-57 induced autophagy in CNE-2 cells.

STM-57 inhibits Bcl-2 and Bcl-xL expression in CNE-2 cells. Anti-apoptotic Bcl-2 family proteins, such as Bcl-2 and Bcl-xL, are well known for their inhibition of autophagy. Bcl-2 and $\mathrm{Bcl}-\mathrm{xL}$ suppress autophagy by binding to the Beclin 1 protein, which is required for the initiation of autophagosomal formation during autophagy. STM-57 inhibited the expression of Bcl-2 and Bcl-xL in CNE-2 cells, whereas the expression of Beclin 1 was increased following STM-57 treatment for $24 \mathrm{~h}$ (Fig. 5A).

STM-57 inhibits the Akt/mTOR pathway in CNE-2 cells. The Akt/mTOR pathway is the main regulator of autophagy. After STM-57 treatment for $24 \mathrm{~h}$, the phosphorylation of 
A

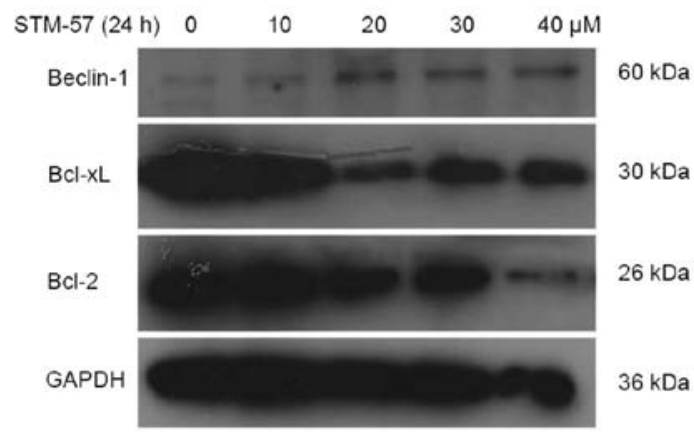

B

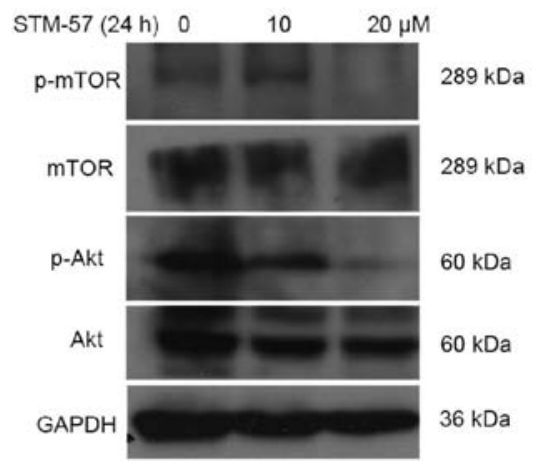

Figure 5. Effects of STM-57 on Beclin 1/Bcl-2 and the Akt pathway in CNE-2 cells. CNE-2 cells were treated with various concentrations of STM-57 for $24 \mathrm{~h}$. The cells were then harvested and lysed. (A) The cell lysates were analyzed by immunoblotting with Beclin 1, Bcl-2 and Bcl-xL antibodies. (B) mTOR, phospho-mTOR, Akt and phospho-Akt levels were analyzed by western blot analysis. The experiment was performed three times.

A

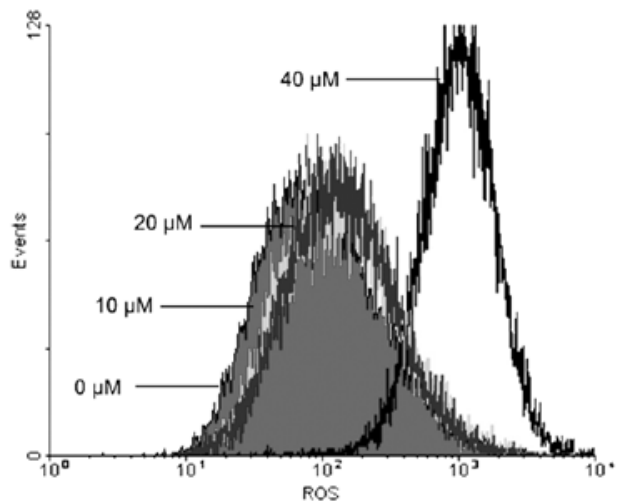

B

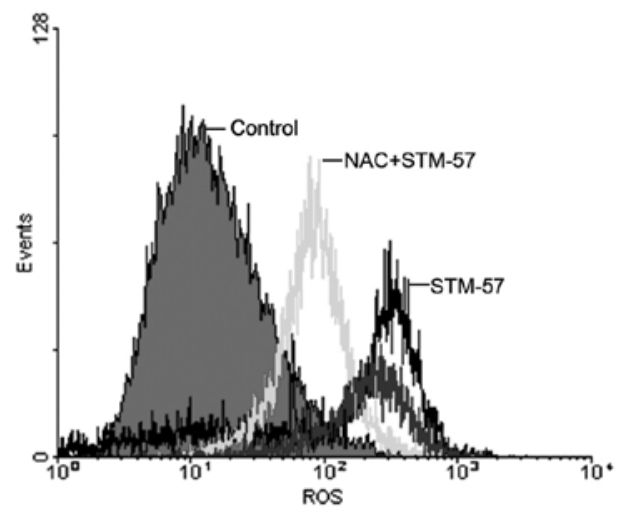

Figure 6. STM-57 induces an increase in ROS levels in CNE-2 cells. (A) CNE-2 cells were treated with the indicated concentrations of STM-57 for $24 \mathrm{~h}$ and the ROS levels were determined by flow cytometry. (B) CNE-2 cells were pre-treated with $100 \mu \mathrm{M} \mathrm{NAC}$ for $1 \mathrm{~h}$ and subsequently treated with $40 \mu \mathrm{M}$ STM-57 for $12 \mathrm{~h}$. ROS levels were determined by flow cytometry.

Akt was inhibited in the CNE-2 cells (Fig. 5B). mTOR is the downstream target of the Akt pathway and plays a key role in autophagy. After STM-57 treatment, the phosphorylation of mTOR was significantly decreased in the CNE-2 cells. These results suggested that the Akt pathway was inhibited by STM-57 in the CNE-2 cells.

STM-57 induces an increase in ROS levels in CNE-2 cells. When the CNE-2 cells were treated with 10,20 or $40 \mu \mathrm{M}$ STM-57 for $24 \mathrm{~h}$, ROS levels were significantly increased in a concentration-dependent manner (Fig. 6A). ROS levels were determined by flow cytometry and expressed in units of mean fluorescence intensity. In the CNE-2 cells, the ROS level was $124 \pm 37.1$ after $40 \mu \mathrm{M}$ STM-57 treatment for $12 \mathrm{~h}$, whereas the ROS level in the control group was $16.4 \pm 2.1$. When the CNE-2 cells were pre-treated with $100 \mu \mathrm{M} \mathrm{N}$-acetylcysteine (NAC) for $1 \mathrm{~h}$ and treated with STM-57 for $12 \mathrm{~h}$, the flow cytometry results showed that NAC partly prevented the increase in ROS levels induced by STM-57 (Fig. 6B). These results suggest that STM-57 induces caspase-independent cell death in CNE-2 cells via ROS accumulation.
STM-57 affects intracellular calcium concentrations, $\Delta \Psi m$ and ATP concentration. When the CNE-2 cells were treated with 10,20 or $40 \mu \mathrm{M}$ STM-57 for $12 \mathrm{~h}$, the intracellular calcium concentrations were significantly increased, whereas the ATP level and the $\Delta \Psi \mathrm{m}$ were decreased (Fig. 7). These results suggest that STM-57 induces caspase-independent cell death in CNE-2 cells via a mitochondrial dysfunction pathway, including ATP depletion, permeability of the mitochondrial membrane and intracellular calcium influx.

\section{Discussion}

The results of this study demonstrate that diaryquinoline compounds exert broad-spectrum anticancer activity in human cancer cell lines. STM-57 induces caspase-independent cell death though autophagy and a mitochondrial-mediated pathway in human cancer cell lines.

Autophagy plays a key role in regulating important cellular functions, such as survival during starvation and the control of infecting pathogens. Numerous multifaceted links between autophagy and cancer have emerged (28). Although 
A

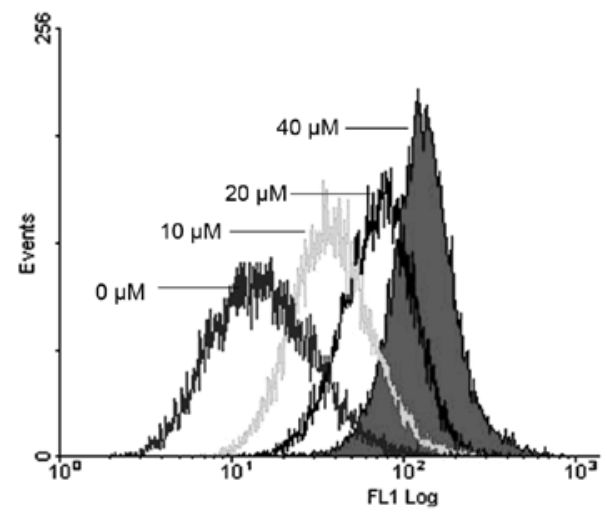

B

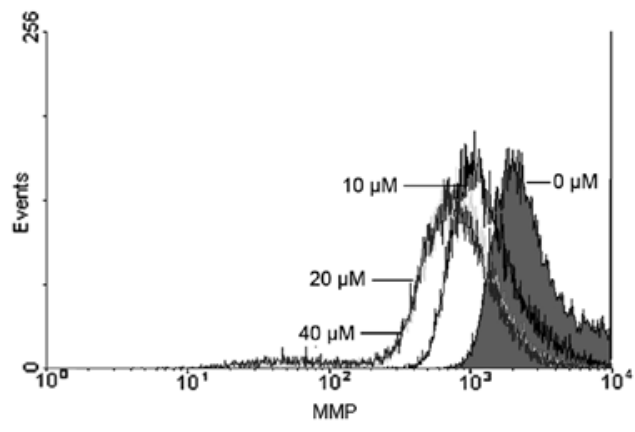

CNE-2

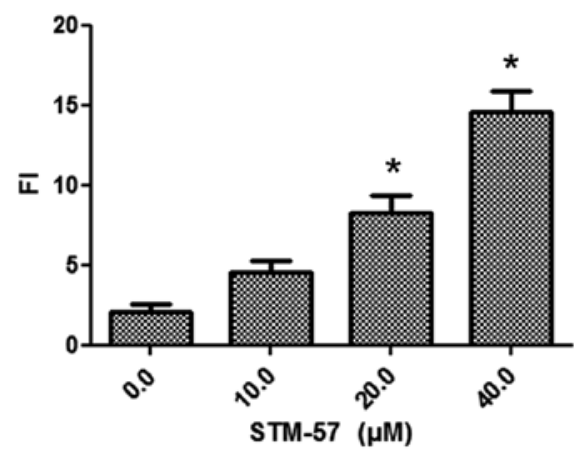

CNE-2

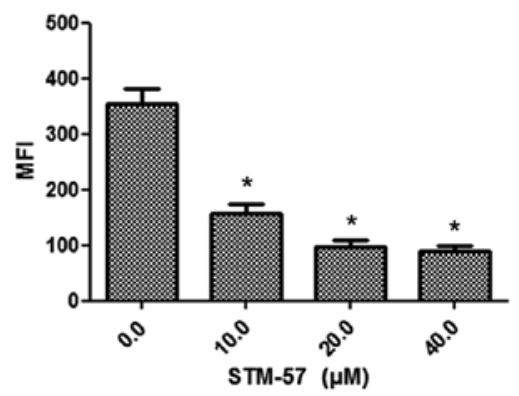

C

CNE-2

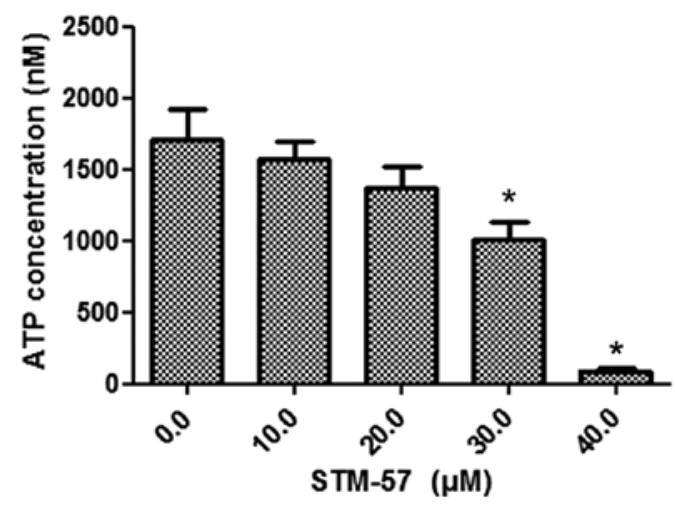

Figure 7. STM-57 affects the intracellular calcium concentrations, $\Delta \Psi \mathrm{m}$ and the ATP concentration. CNE-2 cells were treated with 0 , 10,20 , or $40 \mu \mathrm{M}$ STM-57 for $12 \mathrm{~h}$. (A) The intracellular calcium concentrations were determined in CNE-2 cells with Fluo-3/AM staining. (B) $\Delta \Psi \mathrm{m}$ was determined by flow cytometry. (C) The ATP level was determined with an ATP Assay kit ${ }^{*} \mathrm{P}<0.05$ compared with the control group.

autophagy has been reported as a pro-survival response, in certain instances, the cytotoxicity of cytokines and chemicals in some cell types is mediated by the induction of autophagy. Targeting selected protein kinases involved in the regulation of autophagy using small molecule inhibitors may be a feasible approach in cancer therapy. Previously, imatinib has been shown to induce autophagy in multi-drug-resistant Kaposi's sarcoma and glioblastoma cells (29). The histone deacetylase (HDAC) inhibitor, suberoylanilide hydroxamic acid (SAHA), has also been reported to induce autophagy in HeLa cells independent of caspase activation and apoptosis (30). mTOR inhibitors have been reported to induce autophagic cell death and sensitize various tumor cells to radiation therapy $(31,32)$. It has been reported that quinoline compounds exert potential cytotoxic effects against breast cancer, prostate cancer and colorectal adenocarcinoma (25-27). Therefore, we screened nine newly synthesized diarylquinoline compounds for their cytotoxic effects against cancer cell lines. STM-57 is one of the most potent compounds; it induces non-apoptotic cell death in CNE-2 cells. We further investigated whether the induction of autophagy is required for STM-57-mediated cell death. Autophagic cells enlarge without permeabilization 
of their plasma membrane, convert LC3-I to LC-II, show punctate cytoplasmic LC3 translocation and develop autophagosomes. In this study, CNE-2 cells exhibited morphological and biochemical features characteristic of cells undergoing autophagy, not apoptosis, following STM-57 treatment.

Anti-apoptotic Bcl-2 family proteins, such as $\mathrm{Bcl}-2$ and $\mathrm{Bcl}-\mathrm{xL}$, are frequently overexpressed in cancers (33-35). These proteins inhibit apoptosis by binding to Bax or Bak. Bcl-2 and $\mathrm{Bcl}-\mathrm{xL}$ are also well known for their anti-autophagic abilities. Bcl-2 and Bcl-xL suppress autophagy by binding to the Beclin 1 protein, which is required for the initiation of autophagosomal formation in autophagy $(36,37,12)$. In our study, STM-57 inhibited the expression of Bcl-2 and Bcl-xL in CNE-2 cells, whereas the expression of Beclin 1 was increased following STM-57 treatment. Bcl-2 and Bcl-xL inhibit autophagy by sequestering Beclin 1 from hVps34 and reducing the affinity of the UV radiation resistance-associated gene protein (UVRAG) for Beclin 1 $(38,39)$. Since Bcl-2 and Bcl-xL are localized to the surface of mitochondria, we wished to determine the effect of STM-57 on $\Delta \Psi \mathrm{m}$. Mitochondrial damage plays an important role in apoptosis and autophagy. One hypothesis is that cells respond to mitochondrial damage in a gradual fashion: when only a few mitochondria are damaged, autophagy occurs and the mitochondria are degraded; when more mitochondria are damaged, apoptosis is induced, and the cells die $(40,41)$. We observed that STM-57 decreased $\Delta \Psi \mathrm{m}$ and ATP levels in CNE-2 cells, suggesting that STM-57 induces autophagy via a mitochondrial dysfunction pathway. Høyer-Hansen et al (42) emphasized the important role of $\mathrm{Ca}^{2+}$ in the formation of autophagosomes, and $\mathrm{Ca}^{2+}$ homeostasis and signaling are modulated though Bcl-2 in macro-autophagy. We also observed that STM-57 increased the intracellular calcium concentration in CNE-2 cells, suggesting that STM-57-induced autophagy is associated with an increase in calcium influx. Taken together, these data suggest that STM-57 induces autophagic cell death in CNE-2 cells though a mitochondrial dysfunction pathway, including ATP depletion, permeability of the mitochondrial membrane and intracellular calcium influx.

mTORC1 plays a key role in the repression of autophagy through the integration of different signal inputs. The Akt phosphorylation of TSC2 destabilizes TSC2 and disrupts its interaction with $\mathrm{TSC} 1$, thus abolishing the negative regulatory effect of the TSC2/TSC1 complex on mTORC1 $(43,44)$. In our study, STM-57 inhibited the phosphorylation of Akt in CNE-2 cells. The phosphorylation of mTOR was also dramatically decreased following STM-57 treatment. These results suggest that STM-57 induces autophagy though the inhibition of the Akt/mTOR pathway in CNE-2 cells.

ROS are a class of single-electron reduction products of oxygen, including singlet oxygen, hydroxyl radicals, superoxide and hydrogen peroxide. It has been estimated that $2 \%$ of the oxygen consumed by the mitochondria is converted to ROS (20). The generation of ROS is closely associated with tumorigenesis and treatment. An abnormal increase in ROS levels can promote tumorigenesis. However, an excessive increase in ROS levels can induce the apoptosis and autophagic death of tumor cells, resulting in cancer cell growth inhibition $(45,46)$. In the present study, we found that the treatment of CNE-2 cells with STM-57 led to the production of ROS, and the ROS scavenger, NAC, significantly prevented STM-57-induced cell death, suggesting that ROS accumulation is involved in STM-57-induced autophagy.

In conclusion, the current study demonstrates that STM-57 kills CNE-2 cells via the induction of autophagy. The inhibition of Bcl-2 expression and the Akt/mTOR pathway plays a key role in STM-57-mediated autophagy. STM-57 induces autophagic cell death though a mitochondrial dysfunction pathway, including ATP depletion, permeability of the mitochondrial membrane and intracellular calcium influx. Our study also provides evidence that STM-57 warrants further investigation as a potential anticancer agent.

\section{Acknowledgements}

This study was supported by the National Eleventh Five-Year major technology project (Grant no. 2008ZX09312-002).

\section{References}

1. Wang CW and Klionsky DJ: The molecular mechanism of autophagy. Mol Med 9: 65-76, 2003.

2. Levine B and Klionsky DJ: Development by self-digestion: molecular mechanism and biological functions of autophagy. Dev Cell 6: 463-477, 2004.

3. Høyer-Hansen M and Jäättelä M: AMP-activated protein kinase: a universal regulator of autophagy? Autophagy 3: 381-383, 2007.

4. Meijer AJ and Codogno P: Signalling and autophagy regulation in health, aging and disease. Mol Aspects Med 27: 411-425, 2006.

5. Klionsky DJ and Emr SD: Autophagy as a regulated pathway of cellular degradation. Science 290: 1717-1721, 2000.

6. Abedin MJ, Wang D, McDonnell MA, Lehmann U and Kelekar A: Autophagy delays apoptotic death in breast cancer cells following DNA damage. Cell Death Differ 14: 500-510, 2007.

7. Carew JS, Nawrocki ST, Kahue CN, Zhang H, Yang C, Chung L, Houghton JA, Huang P, Giles FJ and Cleveland JL: Targeting autophagy augments the anticancer activity of the histone deacetylase inhibitor SAHA to overcome Bcr-Abl-mediated drug resistance. Blood 110: 313-322, 2007.

8. Cuervo AM: Autophagy: in sickness and in health. Trends Cell Biol 14: 70-77, 2004

9. Ohsumi Y: Molecular dissection of autophagy: two ubiquitin-like systems. Nat Rev Mol Cell Biol 2: 211-216, 2001.

10. Liang XH, Jackson S, Seaman M, Brown K, Kempkes B, Hibshoosh $\mathrm{H}$ and Levine B: Induction of autophagy and inhibition of tumorigenesis by beclin 1. Nature 402: 672-676, 1999.

11. Liang $\mathrm{XH}, \mathrm{Yu} \mathrm{J}$, Brown $\mathrm{K}$ and Levine B: Beclin 1 contains a leucine-rich nuclear export signal that is required for its autophagy and tumor suppressor function. Cancer Res 61: 3443-3449, 2001

12. Maiuri MC, Le Toumelin G, Criollo A, Rain JC, Gautier F, Juin P, Tasdemir E, Pierron G, Troulinaki K, Tavernarakis N, Hickman JA, Geneste $\mathrm{O}$ and Kroemer G: Functional and physical interaction between Bcl-X(L) and a BH3-like domain in Beclin-1. EMBO J 26: 2527-2539, 2007.

13. Chu CT, Zhu J and Dagda R: Beclin 1-independent pathway of damage-induced mitophagy and autophagic stress: implications for neurodegeneration and cell death. Autophagy 3: 663-666, 2007.

14. He C and Klionsky DJ: Regulation mechanisms and signaling pathways of autophagy. Annu Rev Genet 43: 67-93, 2009.

15. Meijer AJ and Codogno P: Regulation and role of autophagy in mammalian cells. Int J Biochem Cell Biol 36: 2445-2462, 2004.

16. Hay N: The Akt-mTOR tango and its relevance to cancer. Cancer Cell 8: 179-183, 2005.

17. Lum JJ, Bauer DE, Kong M, Harris MH, Li C, Lindsten T and Thompson CB: Growth factor regulation of autophagy and cell survival in the absence of apoptosis. Cell 120: 237-248, 2005

18. Shaw RJ: LKB1 and AMP-activated protein kinase control of mTOR signalling and growth. Acta Physiol (Oxf) 196: 65-80, 2009.

19. Riley PA: Free radicals in biology: oxidative stress and the effects of ionizing radiation. Int J Radiat Biol 65: 27-33, 1994. 
20. Balaban RS, Nemoto S and Finkel T: Mitochondria, oxidants, and aging. Cell 120: 483-495, 2005.

21. Laurent A, Nicco C, Chereau C, Goulvestre C, Alexandre J, Alves A, Levy E, Goldwasser F, Panis Y, Soubrane O, Weil B and Batteux F: Controlling tumor growth by modulating endogenous production of reactive oxygen species. Cancer Res 65: 948-956, 2005.

22. Valencia A and Morán J: Reactive oxygen species induce different cell death mechanisms in cultured neurons. Free Radic Biol Med 36: 1112-1125, 2004.

23. Trachootham D, Zhou Y, Zhang H, Demizu Y, Chen Z, Pelicano H, Chiao PJ, Achanta G, Arlinghaus RB, Liu J and Huang P: Selective killing of oncogenically transformed cells through a ROS mediated mechanism by beta-phenylethyl isothiocyanate. Cancer Cell 10: 241-252, 2006

24. Trachootham D, Zhang H, Zhang W, Feng L, Du M, Zhou Y, Chen Z, Pelicano H, Plunkett W, Wierda WG, Keating MJ and Huang P: Effective elimination of fludarabine-resistant CLL cells by PEITC through a redox-mediated mechanism. Blood 112: 1912-1922, 2008.

25. Thapa P, Karki R, Yoo HY, Park PH, Lee E, Jeon KH, Na Y, Cho WJ, Kwon Y and Lee ES: 2,4-Diaryl-5,6-dihydro-1,10phenanthroline and 2,4-diaryl-5,6-dihydrothieno[2,3-h] quinoline derivatives for topoisomerase I and II inhibitory activity, cytotoxicity, and structure-activity relationship study. Bioorg Chem 40: 67-78, 2012.

26. Muñoz A, Sojo F, Arenas DR, Kouznetsov VV and Arvelo F: Cytotoxic effects of new trans-2,4-diaryl-r-3-methyl-1,2,3,4tetrahydroquinolines and their interaction with antitumoral drugs gemcitabine and paclitaxel on cellular lines of human breast cancer. Chem Biol Interact 189: 215-221, 2011.

27. Metwally K, Aly O, Aly E, Banerjee A, Ravindra R and Bane S: Synthesis and biological activity of 2,5-diaryl3-methylpyrimido[4,5-c]quinolin-1(2H)-one derivatives. Bioorg Med Chem 15: 2434-2440, 2007.

28. Liu B, Cheng Y, Liu Q, Bao JK and Yang JM: Autophagic pathways as new targets for cancer drug development. Acta Pharmacol Sin 31: 1154-1164, 2010.

29. Ertmer A, Huber V, Gilch S, Yoshimori T, Erfle V, Duyster J, Elsässer HP and Schätzl HM: The anticancer drug imatinib induces cellular autophagy. Leukemia 21: 936-942, 2007.

30. Marks PA: Discovery and development of SAHA as an anticancer agent. Oncogene 26: 1351-1356, 2007.

31. Younes A: Therapeutic activity of mTOR-inhibitors in mantle cell lymphoma: clues but no clear answers. Autophagy 4: 707-709, 2008.

32. Kim KW, Hwang M, Moretti L, Jaboin JJ, Cha YI and Lu B: Autophagy upregulation by inhibitors of caspase-3 and mTOR enhances radiotherapy in a mouse model of lung cancer. Autophagy 4: 659-668, 2008
33. Zhou F, Yang Y and Xing D: Bcl-2 and Bcl-xL play important roles in the crosstalk between autophagy and apoptosis. FEBS J 278: 403-413, 2011

34. Sasi N, Hwang M, Jaboin J, Csiki I and Lu B: Regulated cell death pathways: new twists in modulation of BCL2 family function. Mol Cancer Ther 8: 1421-1429, 2009.

35. Walensky LD: BCL-2 in the crosshairs: tipping the balance of life and death. Cell Death Differ 13: 1339-1350, 2006.

36. Yip KW and Reed JC: Bcl-2 family proteins and cancer. Oncogene 27: 6398-6406, 2008.

37. Shimizu S, Kanaseki T, Mizushima N, Mizuta T, ArakawaKobayashi S, Thompson CB and Tsujimoto Y: Role of Bcl-2 family proteins in a non-apoptotic programmed cell death dependent on autophagy genes. Nat Cell Biol 6: 1221-1228, 2004.

38. Pattingre S, Tassa A, Qu X, Garuti R, Liang XH, Mizushima N, Packer M, Schneider MD and Levine B: Bcl-2 antiapoptotic proteins inhibit Beclin 1-dependent autophagy. Cell 122: 927-939, 2005.

39. Noble CG, Dong JM, Manser E and Song H: Bcl-xL and UVRAG cause a monomer-dimer switch in Beclin1. J Biol Chem 283 26274-26282, 2008.

40. Ferri KF, Kroemer G: Organelle-specific initiation of cell death pathways. Nat Cell Biol 3: E255-E263, 2001.

41. Rodriguez-Enriquez S, He L and Lemasters JJ: Role of mitochondrial permeability transition pores in mitochondrial autophagy. Int J Biochem Cell Biol 36: 2463-2472, 2004.

42. Høyer-Hansen M, Bastholm L, Szyniarowski P, Campanella M, Szabadkai G, Farkas T, Bianchi K, Fehrenbacher N, Elling F, Rizzuto R, Mathiasen IS and Jäättelä M: Control of macroautophagy by calcium, calmodulin-dependent kinase kinase-beta, and Bcl-2. Mol Cell 25: 193-205, 2007.

43. Manning BD, Tee AR, Logsdon MN, Blenis J and Cantley LC: Identification of the tuberous sclerosis complex-2 tumor suppressor gene product tuberin as a target of the phosphoinositide 3-kinase/akt pathway. Mol Cell 10: 151-162, 2002.

44. Inoki $\mathrm{K}, \mathrm{Li} \mathrm{Y}, \mathrm{Zhu} \mathrm{T}, \mathrm{Wu} \mathrm{J}$ and Guan KL: TSC2 is phosphorylated and inhibited by Akt and suppresses mTOR signaling. Nat Cell Biol 4: 648-657, 2002 .

45. Schumacker PT: Reactive oxygen species in cancer cells: live by the sword, die by the sword. Cancer Cell 10: 175-176, 2006.

46. Pan JS, Hong MZ and Ren JL: Reactive oxygen species: a double-edged sword in oncogenesis. World J Gastroenterol 15: 1702-1707, 2009 